\title{
ARGENTINA E BRASIL NO ALINHAMENTO DAS PRÁTICAS DE XENOFOBIA: UMA INVESTIGAÇÃO DOS GOVERNOS MACRI E BOLSONARO'
}

\author{
ARGENTINA AND BRAZIL ALIGNING XENOPHOBIA PRACTICES: AN \\ INVESTIGATION OF MACRI AND BOLSONARO GOVERNMENTS
}

DOI: $10.5380 / \operatorname{cg} . V 10 i 3.82466$

\author{
Ludmila Andrzejewski Culpi²
}

Leonardo Mèrcher3

Alexsandro Eugênio Pereira4

\begin{abstract}
Resumo
A imigração tem recebido a atenção da mídia e dos analistas internacionais nas últimas décadas. Contudo, na acolhida dos imigrantes, o que se observa é uma intensificação do discurso xenofóbico e das práticas de controle das entradas dos imigrantes por parte de governos nacionais. Dessa forma, o presente artigo busca investigar a acepção da xenofobia na Argentina e no Brasil, bem como sua presença em discursos que tiveram uma guinada à direita a partir da entrada de Maurício Macri, 2015, e de Jair Bolsonaro, 2019, nos governos nacionais. Busca-se analisar os discursos desses presidentes e as ações políticas voltadas aos imigrantes com o intuito de averiguar se existe um caráter xenofóbico e quais seriam suas práticas de resistência ao estrangeiro, a partir de valores recorrentes. A análise concluiu que a xenofobia está presente em ambos os governos, reproduzindo valores de assimilacionismo, perigos e custos ao Estado. Como resultados secundários observase o alinhamento de valores e práticas entre os governos de Macri e de Bolsonaro no tema, bem como sintonia com outros líderes políticos estrangeiros, como Donald Trump dos EUA.
\end{abstract}

Palavras-Chave: Imigração; Xenofobia; Argentina; Brasil.

\begin{abstract}
Immigration has received the attention of the media and international analysts in recent decades. However, at the level of reception of immigrants, what is observed is an intensification of the xenophobic discourse and practices to control the entry of immigrants by national governments. Thus, this paper seeks to discuss the meaning of xenophobia in Argentina and Brazil, as well as its presence in speeches and public policies that took a right turn from the entry of Maurício Macri, 2015, and Jair Bolsonaro, 2019, into the national governments. We aim to analyze the speeches of both governments and their political actions against immigrants to ascertain xenophobic values and which practices against immigrants they do so. The analysis concluded xenophobia is presented in both governments, reproducing values of assimilationism, dangers and costs to the state. As secondary results, there is an alignment of values and practices between the Macri and Bolsonaro governments on the topic, as well as in tune with other foreign political leaders, such as Donald Trump in the USA.
\end{abstract}

Keywords: Immigration; Xenophobia; Argentina; Brazil.

\footnotetext{
${ }^{1}$ Este artigo está licenciado sob a Licença Creative Commons Attribution (CC BY 4.0), sendo permitido o compartilhamento com reconhecimento da autoria e publicação inicial nesta revista.

${ }^{2}$ Doutora em Políticas Públicas pela Universidade Federal do Paraná e mestre em em Ciência Política pela mesma instituição. E-mail: ludi_culpi@yahoo.com.br. ORCID: https://orcid.org/oooo-0002-1319-2844.

3 Mestre e doutor em Ciência Política pela Universidade Federal do Paraná. E-mail: leomercher@gmail.com. ORCID: https://orcid.org/o000-0003-1812-7803.

4 Doutor em Ciência Política pela Universidade de São Paulo (USP) e professor dos Programas de PósGraduação em Ciência Política e em Políticas Públicas da Universidade Federal do Paraná (UFPR). E-mail: alexsep@uol.com.br. ORCID: https://orcid.org/0000-0002-9613-4702.
} 


\section{INTRODUÇÃO}

Os fluxos de migração humana sempre transpassaram fronteiras políticas e nacionais ao longo da história. Entretanto, governos ainda criminalizam e tratam o outro como uma ameaça nacional. Práticas discursivas e de políticas públicas contendo resistências e perseguição ao estrangeiro podem ser observadas em diversos locais ao redor do mundo atual. Com o intuito de entender um pouco mais sobre esse medo à pessoa estrangeira - xenofobia - é que nós, pesquisadores internacionalistas, nos reunimos no Núcleo de Pesquisa em Relações Internacionais da Universidade Federal do Paraná (NEPRI/UFPR). Ao observarmos a realidade local, percebemos um grande fluxo de imigrantes chegando à cidade de Curitiba, principalmente de origem haitiana e venezuelana. Mas, ao mesmo tempo, percebíamos retrocessos e resistências do governo federal à pauta.

Para entender o local, precisávamos entender o nacional que, por sua vez, nos levou para uma análise de conjuntura regional e global. Discursos resistentes ao estrangeiro foram observados nos governos nacionais da Argentina de Maurício Macri (2015-2019) e do Brasil de Jair Bolsonaro (2019), bem como de outras nações no período, como os EUA de Donald Trump (2016-2020). Mas, para além de discursos, identificamos ainda algumas práticas governamentais que se afinam com o tradicional conceito de xenofobia - o medo ou o ódio ao outro enquanto estrangeiro. Enquanto conceito inicial de xenofobia, utilizamos a definição de que seria "o conjunto de terminologias relacionadas a quaisquer tipos de comportamento de discriminação, desgosto, antipatia e incômodo por parte de indivíduos de um determinado grupo frente a membros de outro grupo" (Haase, Chagas e Arantes, 2009, p. 53). A partir desse conceito, pudemos investigar quais discursos e práticas ambos os governos tiveram em diminuir (discriminar), declarar e reforçar antipatia e incômodo aos grupos estrangeiros enquanto pauta da agenda nacional.

A partir dos discursos e práticas iniciais dos dois governos, percebemos que o estrangeiro discriminado era inserido em pautas de políticas públicas, economia e segurança nacional, em momentos sendo tratados enquanto custos e, em outros, enquanto ameaças aos valores políticos vigentes dos governos em questão. Optamos então por agrupar os dados em duas dimensões de análise: a dimensão da política de gestão; e a dimensão econômica. A dimensão social, ainda que pudesse ser analisada propriamente, é aqui absorvida em ambas as dimensões. Na dimensão da política de gestão, avaliamos indicadores como o espectro político-partidário dos presidentes, seus discursos e práticas de políticas públicas, alterações e menções a normas e portarias jurídicas nacionais, bem como sintonia em valores com outros líderes políticos internacionais, a partir de menções e elogios. Na dimensão econômica, observamos a presença de valores sobre o imigrante enquanto risco ao desenvolvimento nacional e a perda de vagas de emprego para o cidadão local. Para cada dimensão determinados métodos foram combinados para coletar e analisar os dados, desde análise de conteúdo de pronunciamentos até análise de difusão de políticas públicas. 
O foco da pesquisa se dá sobre os discursos e práticas dos governos nacionais da Argentina e do Brasil, a partir da posse de Mauricio Macri (2015) na Argentina até os meses finais de 2020, englobando os dois primeiros anos de governo de Jair Bolsonaro no Brasil. Pensando em uma distribuição das informações da pesquisa de forma mais acessível ao leitor, o presente artigo é então composto pela presente introdução, seguida pela seção conceitual sobre migração, xenofobia, assimilacionismo e outros termos relevantes da pesquisa. Após essa primeira seção, apresentamos a investigação das duas dimensões - política e econômica - para só então apresentarmos nossas considerações finais sobre Argentina e Brasil. Fazemos a ressalva de que ambos os autores aqui manifestam um olhar crítico sobre os dados analisados, bem como sobre a interpretação da xenofobia existente e do assimilacionismo enquanto valores sociais perversos à agenda dos direitos humanos.

\section{BREVE INVESTIGAÇÃO CONCEITUAL DA XENOFOBIA NA AMÉRICA LATINA}

Sabemos que os processos de migração estão presentes ao longo da história. Em alguns momentos, fluxos de estrangeiros eram tidos como problemáticos e, em outros momentos, como algo positivo a ser incentivado. No continente americano, em nosso século XXI, observamos posicionamentos contrários à imigração, seja por parte de grupos sociais, seja por parte de governantes e seus governos. Políticas públicas de resistência ao estrangeiro migrante também podem ser observadas, como trataremos mais adiante. Contudo, para entendermos esse cenário de resistência, é preciso voltarmos ao termo imigração e ao conceito que norteia o nosso trabalho: a xenofobia.

De modo geral imigrante é todo indivíduo que sai de sua localidade estrangeira e entra em uma nova região com intuito de se estabelecer, trabalhar, constituir família ou outra atividade de longo prazo. Dessa forma, o imigrante não necessariamente se refere ao indivíduo que deixa uma nação para entrar em outra, mas também podemos entender migrantes domésticos, como aqueles que migram de uma região para outra no mesmo país. Mas, para delimitação do nosso trabalho, trataremos do imigrante estrangeiro, aquele que deixou sua pátria para tentar a vida na Argentina ou no Brasil.

Ao buscar a definição mais usual em nossa região da xenofobia, podemos iniciar com os estudos da psicologia social sobre o comportamento humano e entender que o medo daquele que não pertence a nosso meio (diferente na religião, na aparência, no idioma, nos hábitos,etc.) nos causa incertezas e pode nos levar ao medo (Haase, Chagas e Andrade, 2009) que, por sua vez, pode gerar ações de resistência e de violência. Seria a xenofobia algo inerente à pessoa humana? Segundo Haase (et al, 2009), não. A xenofobia, assim como o nepotismo, seriam comportamentos evolutivos de adaptação dos indivíduos que se baseiam em sensações naturais, como o medo do desconhecido, 
mas a xenofobia em si não seria naturalmente dada, mas sim condições sociais reproduzidas ao longo da história por determinadas sociedades. Seria só lembrar da recepção de povos originários à chegada de estrangeiros colonizadores, alguns foram receptíveis, e outros, hostis.

Mas como a xenofobia é tratada na América Latina? Em busca de uma orientação, iniciamos uma bibliometria simplificada do termo xenofobia em todos os artigos em português e espanhol na Plataforma Scielo, em julho de 2019. Encontramos alguns estudos que tratavam desde pesquisas empíricas até debates teórico-conceituais. O que conseguimos identificar como recorrente foram: I) estudos da xenofobia exercida pelos EUA sobre imigrantes latino-americanos (Oehmichen, 2018); II) a xenofobia exercida por mexicanos, chilenos, colombianos, argentinos e brasileiros sobre imigrantes latinos (Cantalapiedra, 2019); III) a percepção de que a resistência ao estrangeiro imigrante estaria no medo de que esse pudesse roubar vagas de emprego, diminuir salários e aumentar a marginalização/violência na sociedade (Carrillo Reveles, 2016); IV) o nacionalismo político enquanto meio de fomento e realização da xenofobia (Vásquez Muñoz, 2017); e V) o debate sobre o assimilacionismo, ou seja, a expectativa que o habitante local possui de que o imigrante assimile/copie hábitos, costumes, condutas e valores da comunidade na qual busca se inserir (Gall, 2018).

Apesar dessa breve revisão conceitual na literatura não dar conta de traçar o perfil de todos os casos de xenofobia, ao menos nos dá uma orientação de valores como o medo socioeconômico sobre o estrangeiro e a defesa do assimilacionismo a serem investigados nos dados coletados. Estudos mexicanos se destacam em quantidade na bibliometria, dando tanto foco às relações com os EUA como da própria xenofobia interna a haitianos e outros grupos de imigrantes. O nacionalismo também aparece enquanto ideologia política que reforça identidades e laços dos nacionais em detrimento da exclusão ao "estrangeiro"/diferente. Além disso, grupos sociais e líderes políticos tidos como nacionalistas (Oehmichen, 2018; Gall, 2016 e 2018; Garduño, 2016; Vásquez Muñoz, 2017; Carrillo Reveles, 2016) acabam reforçando valores de que o imigrante rouba empregos e desestabiliza a ordem, a economia e a política nacionais.

Sobre o cenário dos fluxos de imigração nas Américas, assim como os artigos demonstram, é sabido que o principal fluxo de migração latino-americano se destina aos Estados Unidos da América e, em segundo lugar, à Europa (OIM, 2018, p. 84). Entretanto, ao observar os demais fluxos que ocorrem na região, percebe-se que existem outros menores, como de haitianos, venezuelanos, paraguaios e bolivianos que buscaram na Colômbia, Chile, Argentina e no Brasil suas novas moradas nos últimos anos. Até 2015, a Argentina e a Venezuela eram as maiores nações receptoras de estrangeiros da América do Sul (OIM, 2018, p. 86). Entretanto, dada a crise político-econômica venezuelana, o Brasil alcançou o segundo lugar de destino dos imigrantes na região em 2015. Entretanto, proporcionalmente ao número da população total, Argentina continua com o maior índice de acolhimento da população estrangeira, enquanto o Brasil se mantém como um dos menores proporcionalmente a acolhê-los na América do Sul (OIM, 2018, p. 86). 
Outros artigos também apontam para análises de cenário político, como na associação entre discursos xenofóbicos com propostas de mudanças político-econômicas ascendentes (nacionalismos). Exemplos como Donald Trump nos Estados Unidos (Milkman, 2018) podem orientar a enxergarmos o próprio nacionalismo na Argentina e no Brasil em associação com as resistências ao imigrante. Por exemplo, mesmo com as assinaturas dos Acordos de Residência do Mercosul, em 2002, a aprovação da Lei de Migração da Argentina de 2003 e a Nova Lei de Migrações do Brasil de 2017, que retiravam os imigrantes da agenda de segurança nacional e diminuiriam a burocracia dos trâmites, garantindo direitos, os governos de Macri, na Argentina, e Bolsonaro, no Brasil realizaram interpretações próprias desses documentos na hora de pôr em prática as políticas públicas. Essa dinâmica conflituosa entre âmbito das normas e das práticas acaba por se intensificar no cenário de discursos e práticas da chamada nova direita radical na região (Santos e Tanscheit, 2019; Tzeiman, 2021). Mas os casos da Argentina e do Brasil seriam fatos isolados? A partir dessa problemática, inicia-se a investigação das dimensões de análise na seção a seguir.

\section{XENOFOBIA NA ARGENTINA E NO BRASIL: COLETA DE DADOS DOS DISCURSOS E PRÁTICAS DOS GOVERNOS}

Conhecendo um pouco mais sobre as faces da xenofobia na América Latina, bem como valores e pautas que costumam se vincular, iniciamos a coleta de discursos e práticas dos dois governos reconhecidos como da nova direita (Tzeiman, 2021): Maurício Macri (2015-2019), na Argentina, e Jair Bolsonaro (2019-), no Brasil. Destacamos que nosso intuito não é avaliar a trajetória política e a dimensão pessoal desses indivíduos, mas apenas enquanto chefes de Estado e de governo em seus respectivos países, representando um governo para promover posicionamentos e políticas públicas em relação ao imigrante.

Na dimensão política, começamos com uma breve análise de perfil dos dois governantes. Mauricio Macri foi deputado, prefeito da capital nacional, tornando-se presidente, em 2015, pela coligação oposicionista ao governo vigente. De orientação neoliberal (Camargo, 2020, p. 31), negociando os "fundos abutres" (Mars e Cué, 2016) e acalmando o mercado internacional em busca de maior liberalização, aproximando-se de um espectro político de direita argentina. Jair Messias entrou para a carreira militar aos 17 anos e para a reserva em 1988, dedicando-se então à política como vereador e deputado federal pelo Rio de Janeiro (Planalto, 2020). Elegeu-se presidente em 2018, assumindo o cargo em 2019, pela coligação de oposição ao governo vigente, apresentando no governo nacional orientações radicais (Santos e Tanscheit, 2019) entre o nacionalismo seletivo (crítico à China e vizinhos, mas favorável comercialmente aos EUA) e uma agenda econômica de reformas neoliberais (Almeida, 2019, p. 198) proposta por seu Ministro Paulo Guedes. 
Ambos foram classificados como a nova direita, visto que seus governos se opunham aos governos de esquerda anteriores (Kirchner e PT), ao mesmo tempo em que defendem revisões de valores da antiga direita (Santos e Tanscheit, 2019; Tzeiman, 2021), como conservadorismo e críticas a algumas pautas de minorias e de direitos humanos e valorização de valores cristãos e proteção à família (Pecheny, 2019; Almeida, 2019). No Brasil, ocorre ainda a ruptura com o antigo sistema partidário da esquerda (PT) e direita (PSDB), com a ascensão do PSL (Santos e Tanscheit, 2019). Mas e o que dizem sobre os imigrantes? Com essa pergunta, vamos ao primeiro grupo de dados: valores contidos nos discursos dos dois presidentes sobre o tema.

Dos discursos de Macri foram feitas buscas dos seguintes termos no Google: "Macri", "Política Inmigratoria”, "Refugiado", "Inmigrante" e "Xenofobia”. Dos resultados, iremos analisar os vinculados a jornais, agências de notícias e agências nacionais dos governos. No jornal de notícias argentino Clarin foram encontradas mais de 500 notícias de temas correlatos, como a imigração de venezuelanos, mas não manifestações diretas do Presidente. Não pudemos analisar discursos de Macri, pois não identificamos um número grande de discursos presidenciais de Macri em relação ao migrante. Podemos destacar trechos como: "Que venham trabalhar como vieram nossos avós e não alguns que vêm e dão muito trabalho à Ministra de Segurança, Patrícia Bullrich” (LM Neuquen, 2018). Na mesma ocasião o presidente afirmou que defende o princípio da reciprocidade em termos de recepção de imigrantes. Seus trechos sobre migrante acabam apontando para a visão dos mesmos como um obstáculo econômcio em termos de políticas públicas e à sociedade.

Já dos discursos e práticas de Jair Messias Bolsonaro fez-se a análise dos seis discursos oficiais disponibilizados pelo Ministério de Relações Exteriores (MRE, 2019), de o1 de janeiro de 2019 até 27 de setembro de 2019, bem como de suas declarações públicas a partir de 01 de janeiro de 2019 até 06 de outubro de 2019, utilizando busca dos termos "Bolsonaro", "Estrangeiro", "Refugiado", "Imigrante" e "Xenofobia". Foram encontrados 288 na Folha de São Paulo, 169 resultados no Estadão e 133 no O Globo. A grande maioria tratava de temas transversais, como a deportação de Cesare Battisti e políticas públicas aos refugiados venezuelanos.

Resultados de posicionamentos diretos ao estrangeiro, refugiados e/ou imigrantes aparecem duas no ano anterior à posse (período de pré-campanha e campanha), duas já em 2019, e uma indireta (referência), proferida pelo Primeiro-Ministro da República Tcheca. Dos discursos oficiais disponibilizados pelo MRE (2019) destacam-se dois: Discurso do Presidente da República durante Cerimônia de Formatura da Turma do Instituto Rio Branco (Brasília, 3 de maio de 2019); e Discurso de abertura da $74^{\mathrm{a}}$ Assembleia Geral da ONU (Nova York, 24 de setembro de 2019). No primeiro o Presidente Bolsonaro discursa sobre os perigos da Argentina se tornar uma nova Venezuela em crise, ao mesmo tempo em que prossegue defendendo maior abertura do mercado brasileiro aos investimentos estrangeiros. No segundo volta a mencionar a Venezuela, afirmando que da população: 
[...] Todos estão pobres e sem liberdade! O Brasil também sente os impactos da ditadura venezuelana. Dos mais de 4 milhões que fugiram do país, uma parte migrou para o Brasil, fugindo da fome e da violência. Temos feito a nossa parte para ajudálos, através da Operação Acolhida, realizada pelo Exército Brasileiro e elogiada mundialmente. Trabalhamos com outros países, entre eles os EUA, para que a democracia seja restabelecida na Venezuela, mas também nos empenhamos duramente para que outros países da América do Sul não experimentem esse nefasto regime.

Além de associar venezuelanos com pobreza, a pauta neoliberal e a parceria com Donald Trump (EUA) surgem como solução para que o Brasil e demais nações não entrem em uma crise político-econômica. Políticas de isenção de vistos para países como EUA, Japão, Austrália e Canadá, sem contrapartida, também é dito pelo Presidente como meio de se aproximar do desenvolvimento.

Já os pronunciamentos em entrevistas e redes sociais são mais diretos em relação ao estrangeiro. Utilizando o caso francês para criticar a lei brasileira, o então eleito Presidente disse em um encontro com a bancada do partido DEM no Congresso Federal: "Ninguém quer botar certo tipo de gente pra dentro de casa.” (BOL, 2018). Já como Presidente em exercício, Bolsonaro compartilhou em seu Twitter pessoal em o9 de janeiro de 2019:

O Brasil é soberano para decidir se aceita ou não migrantes. Quem porventura vier para cá deverá estar sujeito às nossas leis, regras e costumes, bem como deverá cantar nosso hino e respeitar nossa cultura. Não é qualquer um que entra em nossa casa, nem será qualquer um que entrará no Brasil via pacto adotado por terceiros (ESTADÃO, 2019a).

Em 12 de agosto de 2019, em visita ao Rio Grande do Sul, o Presidente Bolsonaro disse:

Povo gaúcho, se essa esquerdalha voltar aqui na Argentina, nós poderemos ter, sim, no Rio Grande do Sul, um novo Estado de Roraima. E não queremos isso: irmãos argentinos fugindo pra cá, tendo em vista o que de ruim parece que deve se concretizar por lá caso essas eleições realizadas ontem se confirmem agora no mês de outubro. [...] Não se esqueçam que aqui mais ao Sul, na Argentina, o que aconteceu nas eleições de ontem. A turma da Cristina Kirchner, que é a mesma da Dilma Rousseff, que é a mesma de [Nicolás] Maduro e [Hugo] Chávez, e Fidel Castro, deram sinal de vida aqui (GLOBO, 2019).

Essas afirmações acima não são exemplos de xenofobia, mas um ataque a nacionais de países governados por governos de esquerda e indiretamente associam o migrante venezuelano e argentino como alguém que foge por não ter emprego e liberdade, da mesma forma que defende o assimilacionismo para o estrangeiro que aqui buscar viver. A associação entre modelos econômicos (combate ao comunismo), crises, refugiados e problema nacional (para o Brasil) é uma constante em outras manifestações do governo Bolsonaro. O próprio Primeiro-Ministro da República Tcheca, Andrej Babis, após encontro com o Presidente Bolsonaro, 24 de janeiro de 2019 em Davos, afirmou que ele e o brasileiro "compartilham da mesmas ideias sobre imigração" e que, segundo o Estadão (2019b), "Na Europa, Babis tem sido alvo de duros ataques por sua posição, considerada até mesmo 
xenófoba por parte da União Europeia (UE) e de outros líderes [Polônia, Hungria e Eslováquia]”. Além desse alinhamento sobre o estrangeiro, também teriam interesses comerciais em alinhamento (Ibidem).

Indo agora para os dados referentes à elaboração de políticas públicas, por meio da análise de propostas e interpretação das normas pelos governantes, identificamos um grande esforço dos dois governos em reinterpretar as normas domésticas sobre imigração. Como se esperava, os valores nos discursos se reproduzem nas suas práticas de governo. Para compreendermos o cenário da Argentina e do Brasil no âmbito da legislação, devemos retomar o espaço do Foro Migratório do Mercosul que contribuiu para as novas legislações de ambos os países sobre o tema.

Em 2009, com as ratificações dos Acordos de Residência (AR) pelos Estados-membros, foi criada a figura do residente do Mercosul, assegurando direitos a todos os nacionais migrantes do Mercosul, e não apenas aos trabalhadores. Ademais, desde 2011, passaram a ser debatidos assuntos relativos aos direitos dos imigrantes, refugiados e apátridas, com relevante protagonismo da Argentina (Culpi, 2019). Mesmo com as reformas progressivas impetradas pela Lei de Migrações argentina (2003) e a Lei de Migrações brasileira (2017), observa-se o crescimento de práticas antiimigração na Argentina e Brasil (Culpi, 2017).

Tanto Argentina como Brasil, enquanto política de Estado, passaram por reformas jurídicas nacionais nos últimos anos para melhorar e assegurar o cumprimento dos direitos humanos ao estrangeiro. Porém, enquanto políticas de governos, Macri e Bolsonaro dificultaram a aplicação das novas normas nacionais. Maurício Macri, em uma de suas primeiras ações presidenciais, fez o anúncio da construção do Centro para Detenção de Imigrantes e da possibilidade de expulsão dos imigrantes irregulares por crime migratório.

Segundo a Direção Nacional de Migrações da Argentina, em agosto de 2016 houve a criação desse centro para alojar pessoas que infringissem a Lei de Migrações número 25.781, muito semelhante aos campos de detenções (prisões) de imigrantes no sul dos EUA. Organizações sociais, como a argentina CELS, indicaram que essa prática criminalizava o imigrante em situação irregular, o que seria resultado da visão xenofóbica do governo Macri. Essa medida de Macri rompeu com a política migratória argentina vigente até 2016, que era vista como humanamente avançada em relação às demais (Canell, Gavazzo e Nejamkis, 2018).

Em 2017, foi assinado pelo governo Macri o Decreto de Necessidade e Urgência (DNU) $n^{0}$ 70/2017, que permitia a expulsão de imigrantes com antecedentes criminais. Essa decisão foi considerada xenofóbica e inconstitucional pela própria Corte Nacional da Argentina naquele mesmo ano. O Comitê de Proteção a Todos os Trabalhadores Migrantes e suas famílias, dependente da ONU, após analisar vários casos de expulsão na Argentina, emitiu relatório denunciativo desse decreto, exigindo do governo a revisão dos casos de expulsão enquanto inconstitucionais (La Izquiera Diário, 2019). Mesmo assim, Macri continuou e suspendeu o Programa de Abordagem Territorial da Direção Nacional de Migrações, vigente desde 2013, que dava informações aos imigrantes para facilitar seus 
trâmites e regularização. Além disso, cresceram as disposições de expulsão de imigrantes em 70\% em relação ao ano anterior (2015), tendo o governo aumentando o custo das taxas de regularização migratória (Canello, Gavazzo e Nejamkis, 2018).

Já as práticas do governo de Jair Bolsonaro no Brasil iniciaram logo com a saída, em o8 de janeiro de 2019, do Pacto Global para a Migração das Nações Unidas e da assinatura do Tratado de Extradição e Prisões Preventivas com a Argentina (de Macri) - que violariam artigos da Constituição, da Lei de Migração e da Lei de Refúgio por utilizar o conceito aberto de "pessoa perigosa" para facilitar a deportação (Magalhães, 2019).

A visão anti-imigração de Bolsonaro foi reproduzida em algumas decisões como presidente, como a promulgação da Portaria nº 666 de 25.07.2019, do Ministério da Justiça e Segurança Pública. Esse instrumento usava o termo "pessoa perigosa" ao fazer referência ao migrante que será impedido de ingressar no país ou que poderá ser repatriado, deportado sumariamente ou ter cancelada a permissão de permanência. No artigo $2^{\circ}$, destaca que essas pessoas são "aqueles suspeitos de envolvimento" em um rol de delitos indicados na portaria. Nesse caso, o simples fato de haver alguma suspeita já enquadraria o imigrante como "pessoa perigosa”. Esse documento resgata a ideia do paradigma de segurança nacional que embasava o Estatuto do Estrangeiro, a partir de uma desconfiança em relação aos nacionais de outros países. Essa portaria foi revogada pelo ex-juiz e Ministro da Justiça Sérgio Moro em outubro de 2019, após as pressões sofridas por parte da sociedade civil que considerou a decisão inconstitucional. A nova portaria aprovada, no. 770, invalidou a anterior e suavizou as regras sobre deportação.

Em janeiro de 2020, Bolsonaro, em visita oficial à Índia, disse em seu pronunciamento:

A nossa lei de migração é uma vergonha, fui o único a votar contra e fui muito criticado pela imprensa. Eles chegam no Brasil com mais direito do que nós. Isso não pode acontecer, porque devemos preservar o nosso país. Se abrir as portas como está previsto na lei de migração, o país pode receber um fluxo de pessoas muito grande e com muitos direitos. (BOLSONARO, 2020).

O governo brasileiro assumia que primeiro deveríamos resolver os problemas da população brasileira para, só então, poder ajudar refugiados e imigrantes. As tentativas demonstradas acima de dificultar a vida do imigrante e tentativas de reinterpretar a aplicação da nova Lei de Migração (2017), criando mecanismos de segurança (criminalização prévia do imigrante), alinhavam-se para atender a sua base eleitoral mais conservadora, como visto anteriormente em trechos de seus pronunciamentos enquanto Presidente.

Essa base eleitoral se identifica com o presidente e tem traços fortes de conservadorismo e é formada por diversas religiões, indo além da atuação dos evangélicos, participando dessa base conservadora também católicos, outras religiões e atores não religiosos. Um aspecto importante do eleitorado de Bolsonaro é sua pauta anticomunista e anti-Venezuela, o que prejudica e dificulta a integração dos venezuelanos no Brasil (Almeida, 2019). Aliás, a pauta anticomunista no Brasil se 
associa ao nacionalismo de Bolsonaro desde sua campanha, colocando a oposição política no estereótipo de comunistas que não trabalham e vivem do Estado, corrompendo o desenvolvimento nacional. Os vizinhos latino-americanos, enquanto imigrantes, acabam ganhando mais essa alcunha estereotipada nas práticas de xenofobia.

Antes mesmo da eleição de Bolsonaro, durante as consultas públicas sobre a Nova Lei de Migrações, existia um movimento anti-imigração no Brasil que era formado por pessoas com pensamento conservador e que acreditavam que os imigrantes não devem ter um tratamento igual aos nacionais. A xenofobia cresceu nos últimos anos no Brasil, sobretudo por meio de ataques na internet. Entre 2007 e 2019, a Central Nacional de Denúncias de Crimes Cibernéticos recebeu 150.367 denúncias de suspeitas de xenofobia (Intervozes, 2019, p. 21). Esses elevados índices podem ser evidências da relação do discurso de ódio na internet com ataques e manifestações de violência contra imigrantes na realidade (Silva, 2021). Mas em que medida o governo legitima e incentiva esse tipo de comportamento?

O discurso populista de Bolsonaro, que destaca a ameaça comunista e a venezuelização do Brasil, constrói um imaginário, com a invenção de um "inimigo" que ameaça o líder, que mobiliza seus seguidores por meio da internet, no que foi definido como "populismo digital", mediante a difusão das famosas fake news (Silva, 2021). Se não temos como definir se Bolsonaro reflete um grupo ou o alimenta com seu comportamento, ao menos podemos afirmar que seu governo se harmoniza em valores com grupos que discursam e praticam a xenofobia, como em ataques a venezuelanos em Pacaraima em 2018 (Mendonça, 2018). Talvez o fato de argentinos e brasileiros sofrerem e verem cotidianamente atos de xenofobia em países desenvolvidos tenha estimulado o oprimido a oprimir.

Contudo, Bolsonaro, por exemplo, não só criou empecilhos aos estrangeiros, como também aos próprios brasileiros tidos como imigrantes ilegais nos EUA, como aponta a presidente do Centro do Trabalhador Brasileiro nos EUA, Natalícia Tracy (Fellet, 2019). Segundo Tracy, quando Bolsonaro afirma que "a grande maioria dos imigrantes em potencial não tem boas intenções nem quer fazer bem ao povo americano", o presidente brasileiro estaria reforçando o estigma sobre centenas de milhares de brasileiros que vivem nos EUA e enfrentam dificuldades crescentes (Fellet, 2019). Além disso, o governo brasileiro passou a aceitar voos fretados com brasileiros ilegais dos EUA, algo que não era aceito desde 2006 pelos governos anteriores. Suas medidas se associam ao pedido público de Donald Trump, em janeiro de 2020, de que o Brasil deveria ter "uma postura mais agressiva” em relação aos brasileiros que tentam imigrar ilegalmente aos EUA.

Para além do Poder Executivo, a base governista no Poder Legislativo, por meio da Comissão Externa da Câmara dos Deputados, em 11 de maio de 2019, entregou ofício ao Presidente Bolsonaro pedindo prioridade aos brasileiros no atendimento hospitalar e na concessão de benefícios do Bolsa Família (auxílio social) em cidades de Roraima, principal parada dos venezuelanos que atualmente migram para o Brasil (Estadão, 2019c). O documento foi assinado por Nicoletti (PSL-RR), mesmo 
partido na época de Bolsonaro. A diferenciação entre brasileiros e não brasileiros no cumprimento de direitos humanos em território nacional também apontaria o alinhamento entre a base do governo com as ideias da presidência - e descumprimento da Lei de Migração de 2017. Contudo, assim como na Argentina, instituições jurídicas e o ativismo de organismos sociais conseguiram questionar e conter propostas mais radicais dos governos ao imigrante.

Os campos de detenção ao estrangeiro na Argentina, assim como os no sul dos EUA se assemelham em seus discursos e práticas de legitimação. Os discursos colocando o estrangeiro como alguém que rouba o emprego do nacional e que se torna um fardo econômico ao governo também é amplamente defendido nos EUA de Trump, na Argentina de Macri, no Brasil de Bolsonaro, na fala de muitos políticos em situação e oposição dentro da União Europeia. Ainda que os fluxos de migração para Argentina e Brasil não tenham a mesma proporção de recebimento nos EUA e na UE, o alinhamento político e econômico busca falar com as bases eleitorais desempregadas que passam a enxergar no outro a origem dos seus problemas socioeconômicos.

\section{XENOFOBIA E ECONOMIA: SINTONIAS INTERNACIONAIS}

No campo econômico, após a crise econômica internacional, a partir de 2008, os modelos de política econômica, praticados por muitas nações nos anos 2000, como pela Argentina e Brasil, passaram a ser alvos de críticas por novas lideranças políticas em todo mundo. A direita tradicional passou a ser questionada, e novas lideranças e partidos buscavam romper o jogo político para implementar suas pautas econômicas.

O Estado que incentivava o desenvolvimento por políticas sociais começou a ser visto como ineficiente por grupos da sociedade que resgatavam valores econômicos neoliberais, associando investimentos em políticas sociais como caminhos da corrupção do dinheiro público (Almeida, 2020; Tzeiman, 2021). A crítica ao imigrante passa então a ser enquadrada em uma complexidade muito maior do que a local e ganha discursos oficializados de preconceito e xenofobia por diversos chefes de Estado em suas “novas” agendas econômicas. Como resultado, Macri e Bolsonaro aderiram a esse novo movimento e conseguiram se eleger presidentes da Argentina e Brasil, respectivamente.

Essa associação entre discursos xenofóbicos com propostas de mudanças políticoeconômicas ascende em nações como Estados Unidos, com Donald Trump (Milkman, 2018) e aqui na América do Sul, com Macri e Bolsonaro. Portanto, Argentina e Brasil não seriam fatos isolados no mundo. EUA e lideranças de extrema direita, como de Marine Le Pen na União Europeia (Carvalho, 2016, p. 57), por exemplo, uniram pautas xenófobas às pautas econômicas, como do emprego e da austeridade nos custos de políticas públicas. Ao levantarmos os dados das agendas econômicas dos governos de Macri e Bolsonaro, identificamos sintonias com os valores desses mesmos grupos políticos externos, criando uma imagem política composta por autoritarismo 
(Tzeiman, 2021), conservadorismo (Almeida, 2019), nacionalismo e aversão à democracia (Santos e Tanscheit, 2019), desburocratização (diminuição) do Estado no mercado e, em certa medida, valorização do cristianismo (Almeida, 2019; Santos e Tanscheit, 2019) e da meritocracia do bom trabalhador.

A agenda macroeconômica argentina iniciou-se com o plano de austeridade (cortes de gastos públicos), que permaneceu em todo o governo Macri, como Macri defendeu, em $1^{\circ}$ de março de 2019, no Discurso do Estado da Argentina junto ao Legislativo do país. A austeridade seria um dos passos para retirar a Argentina da crise econômica em que se encontrava. O governo eleito executou também empréstimos internacionais com o intuito de estabilizar as políticas cambiais e fiscais para atrair investimentos estrangeiros (Freytes e Niedzwiecki, 2018, p. 125). Macri defendia que o déficit fiscal seria a causa da inflação e pobreza e que os empréstimos com o FMI seriam para alcançar "o déficit fiscal zero" (GZH, 2019).

A partir de 2014 a oscilação de crescimento e queda na Argentina se mostrou uma constante, com crescimento em 2015, 2017 e 2019 e quedas em 2014, 2016 e 2018 (Banco Mundial, 2020). O PIB brasileiro não é tão diferente do argentino, tendo crescimento de 2002 ( $\$ 508$ bilhões) a 2008 ( $\$ 1,696$ trilhão), com queda em 2009 (\$1,667 trilhão), com alta até 2011 (\$2,616 trilhões) e oscilações de queda, em 2012, 2015 e 2018, e de crescimento, em 2013, 2014, 2016 e 2017.

Esse cenário macroeconômico de instabilidades na década de 2010, segundo Pecheny (2019), fortaleceu quatro dimensões articuladas em ambos os países que passam a suportar o modelo econômico e social neoliberal do governo Macri e de Bolsonaro. Segundo o autor, as quatro dimensões seriam: I) avanço dos capitalistas domésticos e globais, com redução das proteções aos trabalhadores; II) crescimento dos atores hierárquicos e autoritários, como religiosos, que lutam para restabelecer uma ordem social; III) a incerteza das classes médias e trabalhadoras diante do rompimento da ordem de certeza do capitalismo de bem-estar e da mobilidade social; e IV) a incerteza gerada pelos esforços exitosos de movimentos sociais que são compreendidos pela classe média como privilégios (Pecheny, 2019).

Essas quatro dimensões, de fato, podem ser observadas como forças políticas que alimentam o medo da população e passam a apoiar as eleições e as agendas econômicas de Macri e Bolsonaro. Muito mais que Macri, Bolsonaro faz uso contínuo de discursos religiosos cristãos às suas bases eleitorais políticas, bem como ambos defenderam em suas reformas um custo menor do Estado e a desregulamentação de diversas áreas de interesses comerciais, como a diminuição burocrática e fiscal ambientais. Posicionamentos contra pautas de movimentos sociais, como dos LGBTQI+, que no Brasil de Bolsonaro foram excluídos da pauta dos direitos humanos do governo (Pecheny, 2019), ou dos pró-vida e contra a descriminalização do aborto na Argentina de Macri, fundem-se em uma força política que implementa a pauta econômica de liberalização e de Estado mínimo em políticas sociais, atingindo diretamente os imigrantes. 
Mas como a agenda econômica explicaria resistências dos dois governos ao imigrante? Em 10 de dezembro de 2018, já como membro do grupo de transição do presidente eleito Jair Bolsonaro, o futuro Ministro das Relações Exteriores, Ernesto Araújo, publicou em seu Twitter: "A imigração é bem-vinda, mas não deve ser indiscriminada. Tem de haver critérios para garantir a segurança tanto dos migrantes quanto dos cidadãos no país de destino. A imigração deve estar a serviço dos interesses nacionais e da coesão de cada sociedade.” (ARAUJO, 2018). Quais seriam os interesses nacionais para o imigrante? Muito provavelmente a resposta poderia ser: produtividade sem custos. O imigrante legal - que prove não ter "más intenções", como Bolsonaro disse -, que invista na Argentina ou no Brasil por meio de seu trabalho ou capital, que não custe em políticas públicas aos governos e que não tenham privilégios, além, é claro da assimilação máxima da cultura e valores nacionais.

Na pauta econômica da desregulamentação dos mercados e políticas de austeridade fiscal (Estado mínimo), o imigrante só seria visto como positivo se viesse a contribuir com a economia. Mas como o cidadão perceberá o imigrante enquanto capaz de contribuir se os governantes os tipificam como desqualificados e ameaças à ordem social? Em um cenário de medos e de constante ansiedade alimentados pelos governantes (Pecheny, 2019), a xenofobia pelo medo de ter seu emprego roubado cresce, e repartir o bolo com quem está chegando de situações de crises humanitárias, como refugiados, parece inviável, provocando mais a competição e os ataques populares que já mencionamos, como contra os venezuelanos.

A falácia da escassez do trabalho é utilizada em momentos de crise econômica para orientar as inseguranças da classe média sobre os imigrantes por determinadas lideranças políticas. Estudos de Bruno e Maguid (2018, p. 107) mostram que, se tirarmos os imigrantes sul-americanos desempregados do país (o maior grupo de imigrantes na Argentina), a diminuição nas taxas de desemprego formal cairia apenas 0,2\% (de 8,4\% para 8,2\%), ou seja, um valor marginal de pouca relevância para se criar políticas nacionais de resistência. No subemprego essa taxa também seria marginal, mas os discursos que associariam os imigrantes à degradação do mercado de trabalho acabam mantendo uma repetição que contribui para um imaginário nacional na Argentina (Ibidem). Já o Brasil, com uma das menores taxas de imigrantes por número de população nacional, provavelmente teria um valor irrisório.

Argentina e Brasil, apesar de estarem em sintonia com alguns valores dos governos do Norte Global, como os EUA de Trump, encontram-se em uma realidade completamente diferente dos países desenvolvidos. Sobre a migração sul-sul, os países do norte se fecham em resistência aos fluxos de imigração alegando desafios econômicos de receberem novos imigrantes, o que desloca muitos desses indivíduos para outras regiões do Sul Global, seguindo a mobilidade do capital e da divisão internacional do trabalho (Baeninger et al, 2018, p. 13). A resistência de governos do Sul Global aos imigrantes, como da Argentina de Macri e do Brasil de Bolsonaro, seria o sonho do oprimido ser opressor? Parafraseando Paulo Freire, é o que podemos observar nas práticas dos 
governos argentino e brasileiro, oprimidos pelo Norte Global e oprimindo os demais povos de seu Sul Global.

A afinidade de agendas macroeconômicas argentina e brasileira de Macri e Bolsonaro com as de nações desenvolvidas, bem como em algumas delas a afinidade dos discursos xenófobos de que o imigrante roubará emprego e trará degradarão do mercado de trabalho - além de custos em políticas públicas - torna-se um revés, em que os próprios argentinos e brasileiros assumem a opressão e a resistência a si próprios em uma hierarquia internacional de povos e transferem essa opressão para os demais vizinhos do sul. Dessa forma, Argentina e Brasil, ainda que por um tempo delimitado por mandatos de governantes, passam a ser agentes construtores de uma estrutura internacional hierarquizada e opressora aos fluxos de migração, utilizando-se de interesses econômicos e agendas afins com o Norte Global.

\section{CONSIDERAÇÕES FINAIS}

O intuito desta pesquisa foi de levantar os posicionamentos dos governos de Mauricio Macri, na Argentina, e de Jair Bolsonaro, no Brasil, em relação ao imigrante em seus respectivos países. Levantando dados políticos e econômicos, como políticas públicas, discursos, valores e índices, foi possível identificar uma sintonia - e talvez alinhamento não formal - entre os governos de Macri e de Bolsonaro no tema. Tanto reproduzindo interesses dos medos domésticos, como em sintonia com líderes internacionais da nova direita, ambos os governantes discursaram resistências ao imigrante e agiram, por meio de políticas públicas, na resistência contra os imigrantes no período analisado (2015-2020).

Na dimensão política, conseguimos explicar que, de fato, existe a presença de valores xenófobos em ambos os governos, originadas tanto nas forças políticas de apoio (ruptura partidária, medos e nacionalismo), como na reprodução sistemática de valores como de que o imigrante possuiria más intensões, seria inferior, possuiria privilégios em relação aos nacionais, não assimilaria a cultura local e se tornaria mais um problema em meio à crise econômica. Na dimensão econômica, valores de austeridade fiscal (corte nas políticas sociais e desregulamentação) versus o medo da degradação do mercado de trabalho com a chegada dos imigrantes - valor sistematicamente repetido, mas que não possui fundamento factual- acabam criando cenários propícios para os tipos de posicionamentos e práticas de ambos os governos analisados.

Para além de discursos, medidas práticas foram tomadas, como a criação do Centro para Detenção de Imigrantes, na Argentina, e a saída do Brasil do Pacto Global de Migração das Nações Unidas, materializando nas agendas de governos a resistência ao imigrante e, até mesmo, sua criminalização prévia, conforme foi praticado por outros governos, como o de Donald Trump. As sintonias com alguns dos posicionamentos e práticas do governo de Trump nos EUA, e com discursos 
de grupos e líderes de extrema direita na União Europeia, como de Marine Le Pen, na França, mostram que Argentina e Brasil, de Macri e Bolsonaro, refletem um movimento global maior do que apenas agendas locais. A xenofobia se coloca como um valor constituído de agendas políticas e, como dito anteriormente, leva tanto a Argentina como o Brasil no período a se tornarem agentes de opressão aos direitos humanos da pessoa imigrante.

Importante discutir a associação entre crescimento da extrema direita no mundo e xenofobia, com ênfase sobre o crescimento deste movimento na Europa. Essa direita é claramente xenófoba e tem ganho mais influência na política europeia. Pode-se afirmar que a atual extrema-direita europeia é muito diversa, com partidos que se declaram neonazistas, como o Aurora Dourada na Grécia, a forças mais bem integradas ao jogo político, como o suíço UDC. O aspecto que os une é que são contrários ao que se chama de globalização "cosmopolita” e são opositores da integração europeia e compartilham entre si também valores de racismo, ódio a imigrantes e ciganos, islamofobia e anticomunismo. Ademais, são defensores de ações autoritárias contra o que denominam "insegurança", que é vinculada diretamente aos imigrantes, com medidas de repressão policial (Lowy, 2015).

Ao contrário da Europa, não existem no Brasil partidos de massa que tenham como bandeira o racismo, pois o racismo difuso está presente na sociedade brasileira. Esse racismo estrutural é um dos fatores responsáveis pelo crescimento dos discursos anti-imigração e da xenofobia. Em termos de pontos de convergência entre a extrema-direita francesa e brasileira, podemos elencar dois aspectos: i) a ideologia da repressão, que no Brasil está representada na "bancada da bala" no Congresso.; e ii) a intolerância em relação às minorias sexuais, sobretudo os homossexuais, muito associada ao poder da igreja evangélica neopentecostal no país (Lowy, 2015).

Não há um apelo claro de combate à imigração como bandeira da extrema-direita brasileira, mas há um crescimento dos discursos e práticas xenófobas dos governos do Brasil e da Argentina, conforme verificado na presente pesquisa.

Ainda que haja diferenças menores entre Macri e Bolsonaro, suas agendas em relação ao imigrante foram e são de resistência. Mas a crise econômica que elegeu Macri também impediu sua reeleição em 2019, perdendo para o atual presidente Alberto Fernández. Fernandéz tomou medidas favoráveis à migração logo após sua eleição. Em 5 de março de 2021, o DNU 70/2017 foi derrogado por ser considerado "irreconciliável com a Constituição Nacional e com o sistema internacional de proteção de direitos humanos”. (ARGENTINA, 2021). Donald Trump também não conseguiu se reeleger em 2020, perdendo para o democrata Joe Biden. Jair Bolsonaro segue seu governo no Brasil sob investigações políticas e crises econômicas devido à quarentena da COVID-19. Contudo, mesmo que governos saiam, suas ações podem permanecer, especialmente no campo da disseminação de valores.

Mesmo que os fluxos de migração para Argentina e Brasil (sul-sul) não tenham a mesma proporção de recebimento nos EUA e na EU (sul-norte), a sintonia política de uma nova direita tenta 
atingir bases eleitorais desempregadas que passam a enxergar no outro a origem dos seus problemas. Dessa forma, os desafios dos imigrantes são muitos, desde superar as origens de sua imigração, passando pela superação dos estigmas e criminalização de sua existência quando não atendem às exigências e expectativas de governos nacionais. A xenofobia enquanto valor na Argentina e no Brasil precisa ser muito mais investigada e tratada, tanto pela academia como pelos próximos governantes.

*Artigo recebido em 16 de agosto de 2021, aprovado em 20 de outubro de 2021.

\section{REFERÊNCIAS}

ALMEIDA, Ronaldo. Bolsonaro presidente: conservadorismo, evangelismo e a crise brasileira. Novos Estudos, CEBRAP, São Paulo, vol. 38, n. 1, p. 185-213, 2019.

ARAÚJO, Ernesto. (@ernestofaraujo). “A imigração é bem vinda, mas não deve ser indiscriminada." 10 dez. 2018, 8:13 pm. Tweet.

BAENINGER, Rosana; et al. (Org.). Migrações Sul-Sul. Campinas: Unicamp / Núcleo de Estudos de População Elza Berquó, $2018 \quad\left(2^{\mathrm{a}}\right.$ edição). Disponível em: https://oestrangeirodotorg.files.wordpress.com/2018/o4/livro-migracoes-sul-sul.pdf; Acesso em: $15 / 11 / 2020$.

Banco Mundial, 2020. World Development Indicators. Disponível em: https://datatopics.worldbank.org/world-development-indicators/; Acesso em: 15/11/2020.

BOL, Brasil Online, 2018. Bolsonaro critica Lei de Migração e fala em barrar "certo tipo de gente". Disponível em: https://www.bol.uol.com.br/noticias/2018/12/12/bolsonaro-critica-leimigracao-certo-tipo-de-gente-dentro-de-casa.htm; Acesso em: 06/10/2019.

BOLSONARO, Jair Messias. Fala do Presidente à Imprensa em Genebra, dezembro de 2018. Reproduzida por Exame, em 20/12/2018. Disponível em: https://exame.com/brasil/embaixadorfrances-ironiza-bolsonaro-apos-critica-sobre-imigracao/; Acesso em: 15/11/2020.

BOLSONARO, Jair Messias. Fala do Presidente à Imprensa na Índia, janeiro de 2020. Reproduzida por BBC News Brasil, em 27/01/2020. Disponível em: https://www.bbc.com/portuguese/internacional-51250357 Acesso em: 15/11/2020.

BRUNO, Sebastián; MAGUID, Alicia. Contribución e impacto de los inmigrantes sudamericanos em el mercado de trabajo de la Argentina. 2018, p. 97-109. (In) BAENINGER, R. et al. (Org.). Migrações Sul-Sul. Campinas: Unicamp / Núcleo de Estudos de População Elza Berquó, 2018 (2 ${ }^{\mathrm{a}}$ edição). Disponível em: https://oestrangeirodotorg.files.wordpress.com/2018/04/livro-migracoessul-sul.pdf; Acesso em: 15/11/2020.

CAMARGO, Felipe Rodrigues. Dos governos Kirchner ao governo Macri: petróleo, soberania e as lógicas territoriais e capitais no conflito geopolítico das Malvinas. Centro de Estudos Geográficos: Finisterra, v. 114, p. 23 -34, 2020. 
CANTALAPIEDRA, Eduardo T. Migración, racismo y xenofobia en internet: análisis del discurso de usuarios contra los migrantes haitianos en prensa digital mexicana. Revista Pueblos., San Cristóbal de Las Casas, v. 14, 401, 2019.

CARRILLO REVELES, Veremundo. Fútbol, nacionalismo y xenofobia en México: debates en la prensa sobre los jugadores extranjeros y naturalizados, 1943-1945. Desacatos, México, n. 51, p. 5069, ago. 2016.

CARVALHO, João. Partidos de extrema-direita e a gestão da crise do asilo na Europa: O caso francês. Relações Internacionais, n. 50, Lisboa, p. 57-69, jun. 2016.

CHEQUEADO. Macri: Todos los días llegan entre 100 y 200 inmigrantes a la ciudad, que no sabemos quiénes son. 10/12/210. Disponível em: https://chequeado.com/ultimasnoticias/macri-todos-los-dias-llegan-entre-100-y-200-inmigrantes-a-la-ciudad-que-no-sabemosquienes-son/. Acesso em: 9/10/ 2019.

CUÉ, Carlos; REBOSSIO, Alejandro. Scioli e Macri, a política dos nascidos em berço de ouro na Argentina. El País Brasil: Eleições na Argentina. Matéria publicada em 26 de outubro de 2015. Disponível em: https://brasil.elpais.com/brasil/2015/10/25/internacional/1445809731 119977.html. ; Acesso em: 12/11/2020.

CULPI, Ludmila. Mercosul e Políticas Migratórias: Processo de Transferência de Políticas Públicas Migratórias pelas instituições do Mercosul a Argentina, Brasil, Paraguai e Uruguai (19912016). Tese (Doutorado em Políticas Públicas), Universidade Federal do Paraná, Curitiba, mar. 2017.

CULPI, Ludmila A. Estudos Migratórios. Curitiba: Editora Intersaberes, 2019.

DAVIDSON, Adam. Desbancando o mito do imigrante que rouba empregos. The New York Times: América. Matéria publicada em 22/05/2015. Disponível em https://www.nytimes.com/2015/03/29/universal/es/desbancando-o-mito-do-imigrante-querouba-empregos.html. Acesso em: 15/11/2020.

ESTADÃO, O Estado de São Paulo, 2019a. "Não é qualquer um que entra em nossa casa", diz Bolsonaro sobre migrantes. Por Daniel Weterman, o9 de janeiro de 2019. Disponível em https://politica.estadao.com.br/noticias/geral,nao-e-qualquer-um-que-entra-em-nossa-casa-dizbolsonaro-sobre-migrantes,70002672727; Acesso em: 06/10/2019.

ESTADÃO, O Estado de São Paulo, 2019b. Bolsonaro se alinha a grupo anti-imigração da União Europeia. Disponível: em https://internacional.estadao.com.br/noticias/geral,bolsonarose-alinha-a-grupo-anti-imigracao-da-uniao-europeia,70002692469; Acesso em: 06/10/2019.

ESTADÃO, O Estado de São Paulo, 2019c. Deputados do PSL pedem que governo privilegie brasileiros na fronteira com Venezuela. Disponível em: https://politica.estadao.com.br/blogs/coluna-do-estadao/deputados-do-psl-pedem-que-governoprivilegie-brasileiros-na-fronteira-com-venezuela/; Acesso em 7/10/2019.

FELLET, João. Não bastasse Trump, agora Bolsonaro nos cria dificuldades. BBC Brasil, 19/o9/2019. Disponível em https://www.bbc.com/portuguese/brasil-47619269. Acesso em: $15 / 11 / 2020$.

FREYTES, Carlos; NIEDZWIECKI, Sara. Argentina 2017: la dinámica intertemporal de la reestructuración económica. Revista Ciencia Política, Santiago, v. 38, n. 2, p. 125-154, ago. 2018.

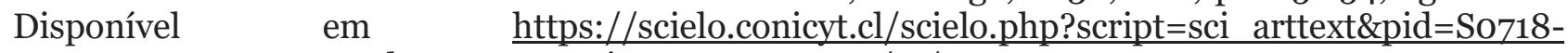
090X2018000200125\&lng=es\&nrm=iso Acesso em: 15/11/2020. 
GALL, Olivia. Hilando fino entre las identidades, el racismo y la xenofobia en México y Brasil. Desacatos, México, n. 51, p. 8-17, ago. 2016.

GALL, Olivia. Racismos y xenofobias mexicanos frente a los migrantes: 1910-2018. REMHU, Brasília, v. 26, n. 53, p. 115-134, Ago. 2018.

GAZETA DO POVO, 2019. Eleições 2018: Bem antes de Trump, Bolsonaro chamou haitianos e outros imigrantes de "escória do mundo". Disponível em: https://www.gazetadopovo.com.br/politica/republica/eleicoes-2018/bem-antes-de-trumpbolsonaro-chamou-haitianos-e-outros-imigrantes-de-escoria-do-mundobvhv8jcogsf15ueai7od4uyol/; Acesso em: 6/10/2019.

GLOBO, O Globo, 2019. Bolsonaro diz que argentinos fugirão para o Brasil se "esquerdalha" voltar ao poder no país vizinho. Disponível em: https://oglobo.globo.com/mundo/bolsonaro-diz-que-argentinos-fugirao-para-brasil-seesquerdalha-voltar-ao-poder-no-pais-vizinho-23871472; Acesso em: 6/10/2019.

GZH, Gaúcha Zero Hora Mundo; Agence France-Presse. Macri defende plano de austeridade apesar de crise econômica na Argentina. Matéria publicada em 01/03/2019. Disponível em https://gauchazh.clicrbs.com.br/mundo/noticia/2019/03/macri-defende-plano-de-austeridadeapesar-de-crise-economica-na-argentina-cjsqc66eo01vro1t4dj6cogl8.html Acesso em: 15/11/2020.

HAASE, Vitor G.; CHAGAS, Pedro P.; ARANTES, Érika A.; A natureza e a criação da xenofobia: uma perspectiva da neurociência cognitiva social. Gerais: Revista Interinstitucional de Psicologia, UFMG: Juiz de Fora, v. 2, n. 2, p. 53-66, dez. 2009. Disponível em http://pepsic.bvsalud.org/scielo.php?script=sci arttext\&pid=S1983-82202009000200002

Acesso em 18/05/2021.

INTERVOZES. Coletivo Brasil de Comunicação Social. Desinformação: ameaça ao direito à comunicação muito além das fake news. São Paulo: Intervozes, 2019.

LM NEUQUEN. Maurício Macri dijo que los extranjetos vengan trabajar no darle tranbajo a Bullrich. Disponível em: https://www.lmneuquen.com/mauricio-macri-que-losextranjeros-vengan-trabajar-no-darle-trabajo-bullrich-n611491. Acesso em: 9/10/ 2019.

LOWY, Michael. Conservadorismo e extrema-direita na Europa e no Brasil. Serv. Soc. Soc., OctDec, 2015.

MAGALHÃES, Vera. Defensoria da União diz que portaria viola Constituição. BR Político, 27/07/2019. Disponível em: https://brpolitico.com.br/noticias/defensoria-da-uniao-diz-queportaria-viola-constituicao/; Acesso em: 06/10/2019.

MARS, A.; CUÉ, Carlos. Argentina sela acordo com "fundos abutre" para encerrar 14 anos de conflito. País Internacional. El País Brasil: Internacional. Matéria publicada em 29 de fevereiro de 2016. Disponível em: https://brasil.elpais.com/brasil/2016/o2/29/internacional/1456758816 843479.html; Acesso em: 12/11/2020.

MENDONÇA, Heloísa. O "monstro da xenofobia" ronda a porta de entrada de venezuelanos no Brasil: após ataque a imigrantes em Pacaraima, divisa com a Venezuela, refugiados expõem medo e brasileiros revoltados cobram soluções. (In) Êxodo venezuelano, El País. Publicado em 27/08/2018. Disponível em: https://brasil.elpais.com/brasil/2018/08/17/politica/1534459908 846691.html Acesso em: 18/05/2021. 
MILKMAN, Ruth. Trump and the future of U. S. Labor: an intersectional perspective. Novos Estudos CEBRAP, São Paulo, v. 37, n. 1, p. 99-115, Abril 2018.

MRE, Ministério das Relações Exteriores, 2019. Presidente da República Federativa do Brasil - Discursos. Disponível em: http://www.itamaraty.gov.br/pt-BR/discursos-artigos-e-entrevistascategoria/presidente-da-republica-federativa-do-brasil-discursos; Acesso em: 06/10/2019.

NUNEZ, Paula Gabriela; BARELLI, Ana Inés. Marcas urbanas y sentidos sociales en disputa. San Carlos de Bariloche, Argentina 1966-1983. Historelo, Revista de Historia Regional y Local, Medellín, v. 5, n. 10, p. 164-196, dez. 2013.

OEHMICHEN, Cristina. Los imaginarios de la alteridad y la construcción del chivo expiatorio: Trump y el racismo antinmigrante. Revista Pueblos, San Cristóbal de Las Casas, v. 13, e344, dez. 2018.

OIM, Organização Internacional para Migração, 2018. Informe sobre las migraciones en el mundo 2018. Disponível em https://publications.iom.int/books/informe-sobre-las-migracionesen-el-mundo-2018. Acesso em: 06/10/2019.

Pecheny, Mario Martín. Restaurações conservadoras na Argentina e no Brasil: o íntimo e o público sob ataque. Interface, Botucatu, v. 23, 2019.

Planalto, Governo Federal do Brasil. Biografia do Presidente, 2020. Disponível em https://www.gov.br/planalto/pt-br/conheca-a-presidencia/biografia-do-presidente. ; Acesso em $12 / 11 / 2010$.

Relatório RAIS 2019. SIMÕES, A; et. al. Relatório RAIS: A inserção socioeconômica dos imigrantes no mercado de trabalho formal. Observatório das Migrações Internacionais; Ministério da Justiça e Segurança Pública/ Coordenação Geral de Imigração Laboral. Brasília, DF: OBMigra, 2019. Disponível em: https://portaldeimigracao.mj.gov.br/images/dados/relatorios RAIS/Relat\%C3\%B3rio RAIS.pdf Acesso em: 15/11/2019.

SANTOS, Fabiano; TANSCHEIT, Talita. Quando velhos atores saem de cena: a ascensão da nova direita política no Brasil. Colomb.int., Bogotá, n. 99, p. 151-186, Jul. 2019.

SILVA, Izabel da. "BOTA FOGO NESSES VAGABUNDOS!": ENTEXTUALIZAÇÕES DE XENOFOBIA NA TRAJETÓRIA TEXTUAL DE UMA FAKE NEWS. Trab. linguist. apl., Campinas, v. 59, n. 3, p. 2123-2161, Set. 2020.

TZEIMAN, Andrés. Estado y autoritarismo en Argentina: el debate sobre la "nueva derecha". Revista Katálysis, Florianópolis, v. 24, n. 1, p. 33-42, Abr. 2021. 